\title{
Four-Cable-Plane Spatial Cable Stayed Bridge with Two- Amplitude Curved Deck for Canyon-River
}

\author{
Jilin Wang ${ }^{1 *}$ and JinFa $\mathrm{Xu}^{2}$ \\ ${ }^{1}$ China Design Group Co., Ltd, Nanjing, China, 210007 \\ ${ }^{2}$ Jiangsu traffic engineering consulting and Supervision Co., Ltd, Nanjing, China, 211800
}

\begin{abstract}
On the basis of the original design of Ruck Bridge by Mr. Lin Tongyan, this paper modifies the single-amplitude curved cable-stayed bridge of Ruck Bridge to be an elliptical ring main beam of twoamplitude curved deck, with a duck-egg-shaped arch tower and a spatial cable net with four cable planes, to form a spatial four-cable-plane two-amplitude-curve cable-stayed bridge for the canyon-river topography, so as to improve the structural stress performance of the curved-beam cable-stayed bridge, promote the traffic function and improve the landscape. Combined with the 400m-span New Ruck Cable-stayed Bridge, engineering parameters are designed, a Midas finite element analysis model is established, and the dynamic modal analysis is carried out to verify the structural superiority of this new four-cable-plane spatial cablestayed bridge with two-amplitude curved deck.
\end{abstract}

\section{Introduction}

Under the topographic conditions of canyon rivers, the highway is usually designed as a parallel river. If the curved cable-stayed bridge structure is adopted for the bridge across the river, very favorable conditions can be created for the road line selection, bringing extremely reasonable and economic results ${ }^{[1-2]}$.

As early as 1977, T.Y Lin will provide a design scheme of curved cable-stayed bridge (firm), the firm bridge cable according to the space space hyperboloid anchoring on side slopes, the layout of regular use of the hills on both sides of the superior geological conditions to serve as a powerful anchor structure, in order to balance the load of the bridge, four space on the surface of the cable tension replaces the bridge pier, bear the load of the whole bridge, firm bridge selects the curved cable-stayed bridge was a lot of the stone or tunnel and thus can save millions of dollars, and curved cable-stayed bridge structure itself and the environment to bring out the best in each other beautiful shape ${ }^{[3-4]}$.

The main reasons for the failure of Ruck bridge are as follows: Ruck bridge combines curvilinear main beam with cable-stayed bridge. The structure is complex, and the curvilinear main beam is subjected to the composite action of bending moment, shear force and torque at the same time. The cable design, calculation and analysis are difficult $^{[5-6]}$, and the internal force balance control during construction is very difficult.Ruck bridge cable cable is scattered anchoring on the hillside, the construction is complicated, and the maintenance is quite difficult.Due to the operation effect of the horizontal curved arch structure, the stress of the basic structure is unbalanced ${ }^{[7-8]}$.
River canyon topography of high grade highway, the author of this paper long-span curved cable-stayed bridge across the river, draw lessons from four cable plane cablestayed bridge of double image design concept, improve firm single curved cable-stayed bridge for elliptic ring type double amplitude curve girder, set the duck eggs arch bridge tower, the arrangement of four network cable plane, space, form a river canyon terrain plane, the space of four double curved cable-stayed bridge, improve the structure performance, improve the traffic function, improve the landscape effect.

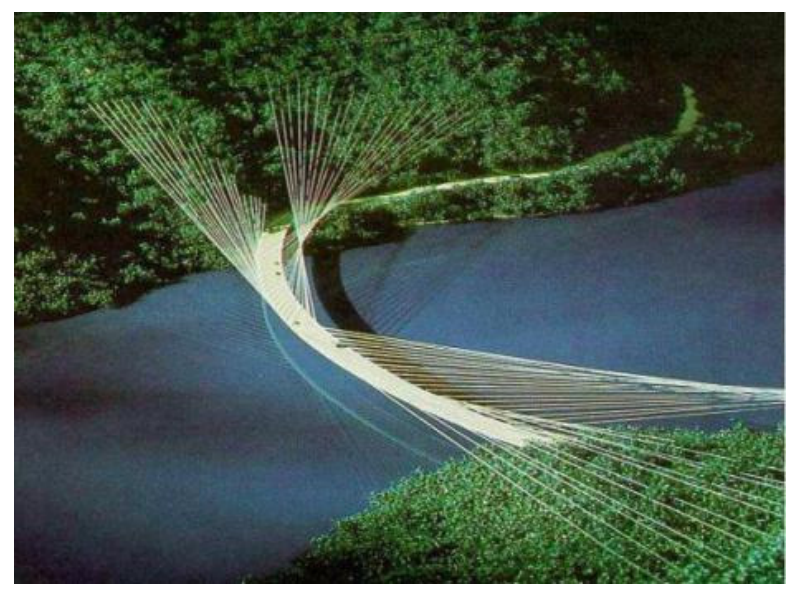

Figure 1. Lin Tongyan Ruck bridge design

Combined with the improvement requirements of the original Ruck Bridge design with a span of 400 meters, the structural configuration of the New Ruck Bridge with a four-cable plane and two-amplitude curvilinear cablestayed Bridge with canyon river terrain was studied,

\footnotetext{
*Wang Jilin: 37386492@qq.com
} 
engineering parameter design was carried out, and a Midas finite element analysis model was established, so as to verify the superiority of the New structure with a four-cable plane and two-amplitude curvilinear cablestayed Bridge with a span of four meters.

\section{Configuration study}

And because the original highway is built along the river and along the mountain, if a straight line bridge is built, the highway on both sides must be changed, will be faced with digging a large number of stone works or tunnel construction, huge investment.

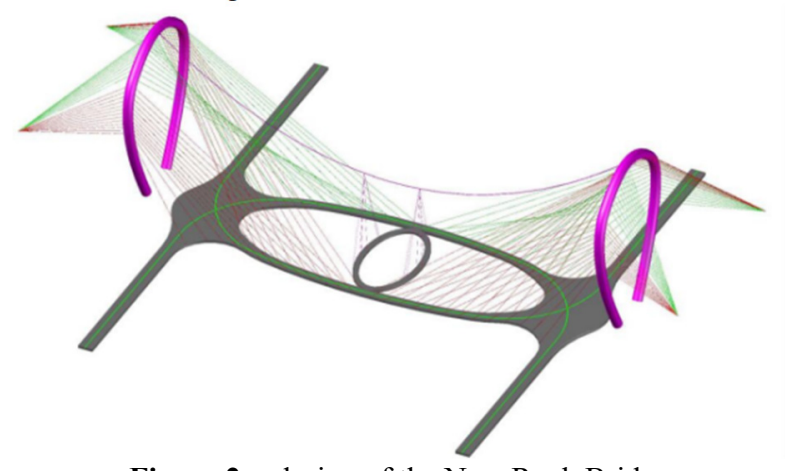

Figure 2. design of the New Ruck Bridge

The design of New Ruck Bridge refers to the design concept of the four-cable-stayed Bridge, and the singlecable-stayed Bridge of the Ruck Bridge is improved to be the main beam of the elliptic-ring double-cable-stayed Bridge. The duck egg arch Bridge tower is set up, and the spatial cable-stayed Bridge of the four-cable-stayed Bridge is arranged to form the double-ring cable-stayed Bridge, so as to improve the traffic function and improve the landscape effect.

Compared with the original Ruck Bridge with a single curved main beam, the New Ruck Bridge adopts the elliptic circular double-curved main beam with symmetric left and right structure, which can greatly reduce the torque in the main beam. The horizontal internal force of the left and right curved main beam is self-balanced, which makes the cantilever construction method feasible indeed, safe, simple and feasible.

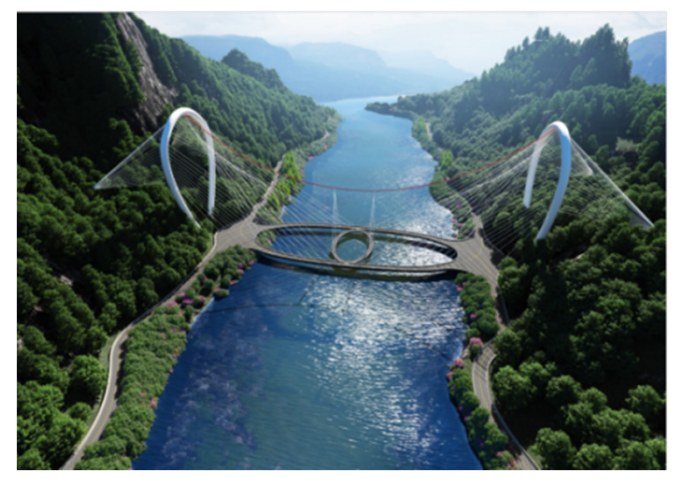

Figure 3. Renderings of the New Ruck Bridge

New Ruck Bridge adopts duck egg arch Bridge tower. According to egg-shaped curve equation, steel pipe segments are processed by stewing and bending by fire workers, welded and assembled at the construction site to form egg-shaped steel pipe arch ribs. Egg-shaped steel pipe arch ribs are placed by hoisting egg-shaped steel pipe, and high-strength concrete is poured into the steel pipe to form egg-shaped concrete pipe arch tower.

The duck egg arched bridge tower has excellent mechanical performance and very beautiful shape. The duck egg arched bridge tower has good visual effect and beautiful shape curve. On the hillside, the duck egg arched bridge tower is set up and the hyperboloid space cable cable network with four cable faces is anchored, which is very beautiful and harmonious with the surrounding mountain and canyon environment.

The duck egg arch bridge tower anchors the four-cable plane space cable, and the double-width four-cable plane space curved cable tightly holds the elliptic ring doublecurved line main beam, forming the hyperboloid space cable network, which is simple in structure, rich in facade and beautiful in shape.

Elliptic circular double-bent main beam, duck egg arch bridge tower and four-cable space cable are all curvilinear structures, which are cleverly coordinated and graceful, making cable-stayed bridge present a special curvilinear beauty and bringing out the best in each other. The four-cable space cable has a novel and unique shape, which is an ideal combination of structural science and architecture.

Single main cable suspended between two oval arch bridge tower, in the construction phase, a similar cable hoisting method of concrete filled steel tube arch bridge, in the picture around the elliptical ring double curved lines between girders set several temporary connecting steel truss beam, main single cable suspension cable connecting tightly capture steel truss beam, ensure that the elliptical ring double curved girder of the linear segment suspension structure in the process of cantilever construction smoothly, to ensure that the construction of avoid elliptic ring double curved girder structure lifting reverse phenomenon, through the cable hoisting method auxiliary cantilever construction, until the folded cantilever bridge.

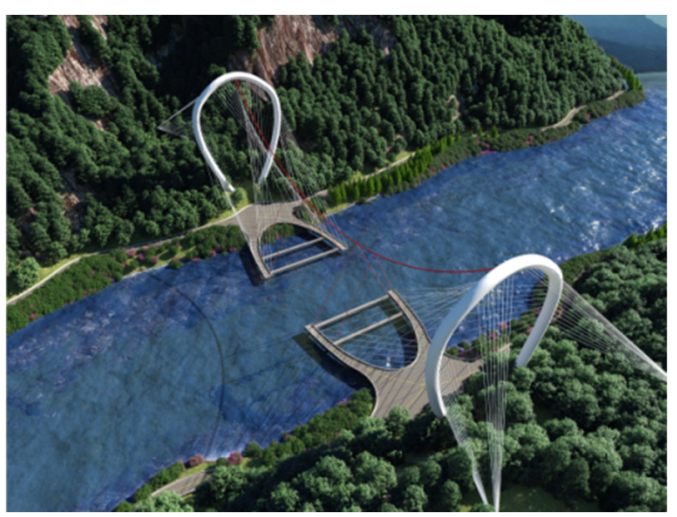

Figure 4. Cantilever assembly construction

After a bridge, single main cable suspension cable central set several radial oblique sling, bear the weight of the oval ring beam, safe and reliable to ensure the central oval ring beam stress, the central circle beam as the poles artifacts, limit the lateral deformation of elliptic ring 
double curved girder, increase the integrity of bridge deck structure and at the same time, the central oval ring beam and a sightseeing platform.

\section{Parameter design}

The New Ruck Bridge adopts the New technology of cable-stayed Bridge with four cables and two curves in the space of canyon river topography. The design load is highway 2 and the river is 400 meters wide.
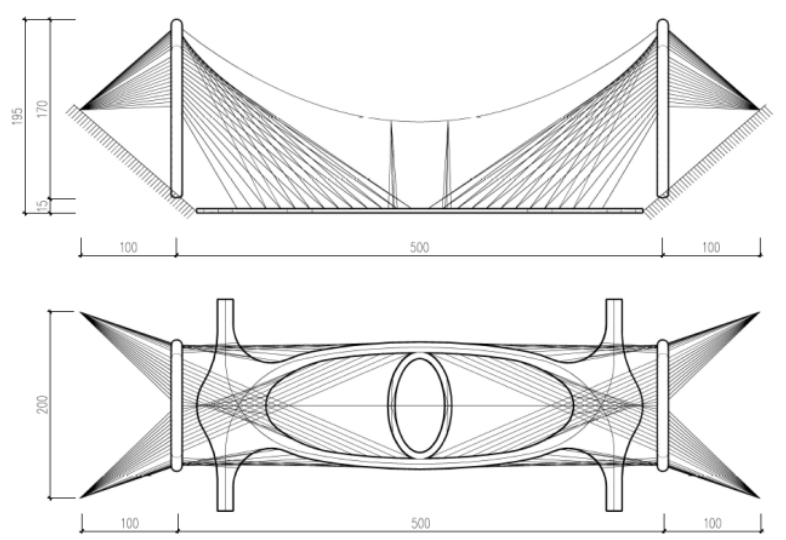

Figure 5. General design of the New Ruck Bridge

The distance between the two arched bridge towers is 500 meters, the height of the arched bridge tower is 170 meters, and the widest part of the bridge tower is 130 meters. The arched bridge tower adopts circular steel tubes with a diameter of 10 meters, the thickness of the steel pipe is $40 \mathrm{~mm}$, and C60 concrete is poured inside.

The elliptic circular double-amplitude curved main beam is composed of the elliptic curved deck section, the connecting transition bridge section and the curved cantilever plate. The elliptic curved deck section is the curved composite box girder with single box and doublechamber corrugated steel webs. The beam is 3 meters high and the width of the double-width bridge deck is 10 meters wide.

The connection bridge deck is made of reinforced concrete slab with a thickness of 3 meters. The curved cantilever plate is 0.4 meters thick reinforced concrete slab, and the curved cantilever plate is embedded to support the hillside body.

Elliptic ring type double amplitude curve girder central set elliptic ring beam, oval ring beam supporting elliptic ring double amplitude so that both of elliptical arc of curved girder bridge deck section of the inside of the bridge deck, oval ring beam and a sightseeing platform, oval ring beam for ordinary steel box girder structure, the oval ring Liang Liang is 2.5 meters high, width of 5 meters.

Four cable plane space is divided into four regions anchorage cable on the oval arch bridge tower, four cable plane space network cable from the inside of the cable net and the outer cable network, the inside of the cable net anchorage in the oval curve arch bridge tower inflection point on the top section of the above, the lateral cable network anchor in the oval curve arch bridge tower on top of the inflection point of the following sections, including the inside of the anchor cable network using cross way.
The distance between anchor points on the deck of the four cable planes is 15 meters, and the diameter of the cable is $0.15 \sim 0.20$ meters from the end of the beam to the middle of the span. One end of the diagonal cable network is dispersed and anchored on the arch tower of the duck egg, and the other end is divided into two sides and anchored in the anchorage.

The single main cable suspension cable is arranged between two arched bridge towers. The diameter of the single main cable suspension cable is 0.5 meters for the finished cable of high strength steel wire.

After the completion of the bridge, the temporary connecting beam was removed, and the single main cable suspension cable was set with a radial sling. There were a total of 12 high-strength steel cable cables, with each cable having a diameter of 0.1 meters and an elliptic ring beam in the middle of the suspension.

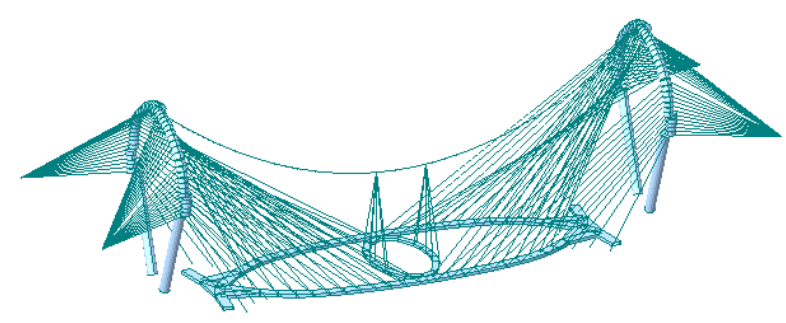

Figure 6. Midas finite element model

\section{Calculation results under vertical load}

The main span bridge deck is loaded with full load, the additional constant load of the bridge deck adopts the uniformly distributed load standard value of $5 \mathrm{kN} / \mathrm{m} 2$, and the live load of the bridge deck adopts the highway second-level load standard value. The internal force of the stiffened beam under direct load is analyzed in the model.

The calculation results are as follows:

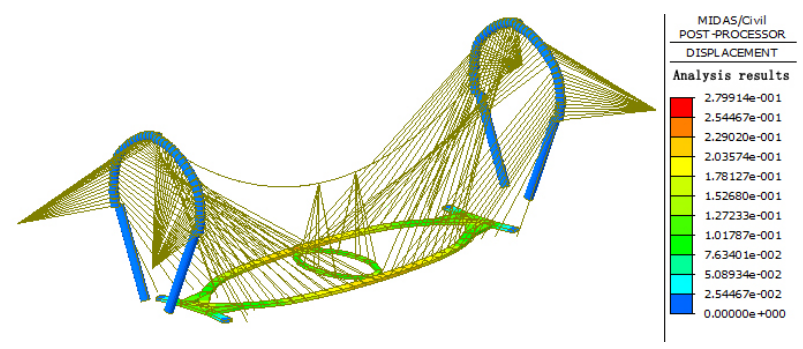

Figure 7. Calculation results of displacement under vertical load (dead load+live load)

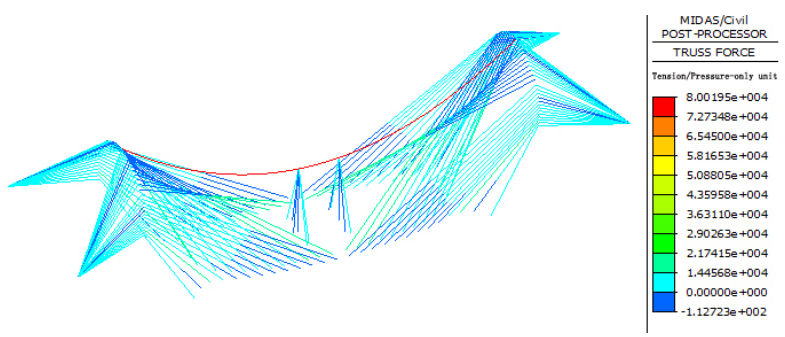

Figure 8. Calculation result of cable internal force (dead load+live load) 


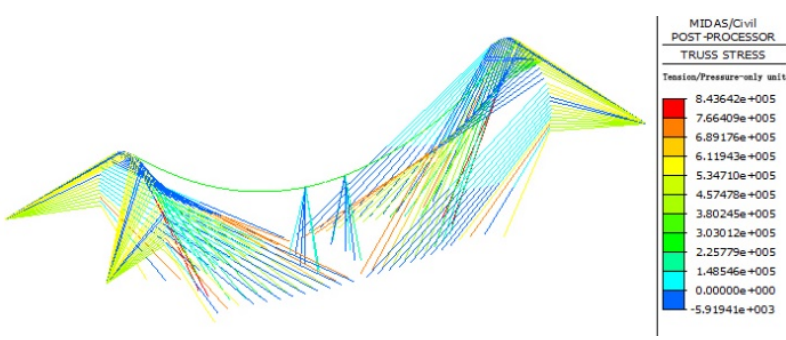

Figure 9. Calculation results of cable stress (dead load+live load)

The maximum vertical displacement occurs in the middle of the span, and the maximum displacement is $0.280 \mathrm{~m}$, which meets the requirement of $1 / 500$ limit specified in the specification.

The internal force of single main cable suspension is $80019 \mathrm{kN}$, and the stress is $407 \mathrm{MPa}$, which meets the strength requirements.

The maximum internal force of the stay cable is $18758 \mathrm{kN}$, and the maximum stress of the stay cable is 933.0mpa, which meets the strength requirement.

The analysis shows that: under the vertical load, the stress of New Ruck Bridge is symmetrical, and there is no great torsion deformation.

\section{Dynamic modal analysis}

Cable is the main load-bearing structure of cable-stayed bridge, the influence of gravity stiffness must be considered in the dynamic characteristic analysis, and the internal forces of main cable and sling should be calculated in the form of initial tension force in the modeling.

Based on Midas nonlinear static analysis, stressrigidity effect and modal analysis function, the natural vibration characteristics of the structure were analyzed. In order not to omit any mode, the subblock method is used to solve the characteristic equation.

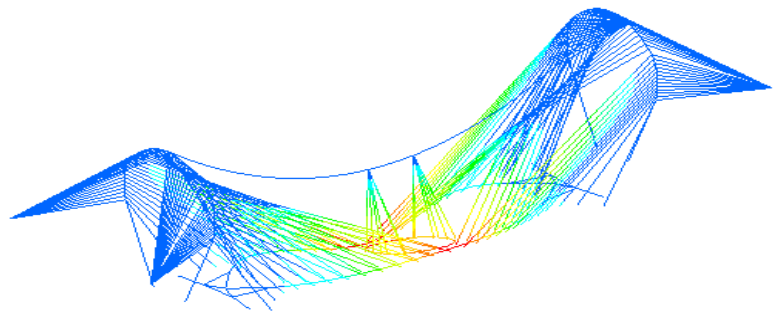

(a) 1 order mode $(0.740 \mathrm{HZ})$

(Positive symmetrical side bend)

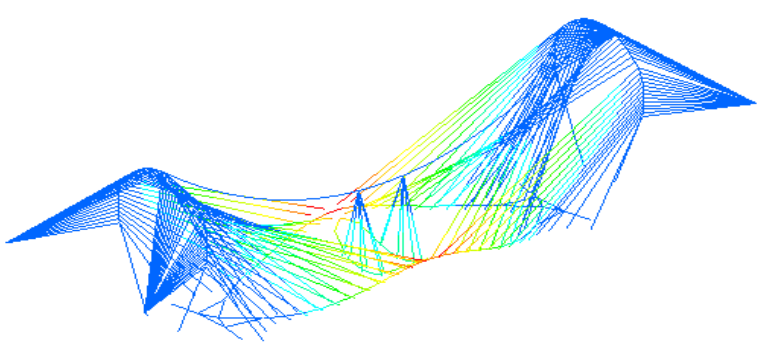

(b) 2 order mode $(0.790 \mathrm{HZ})$

(Positive symmetric vertical bending)

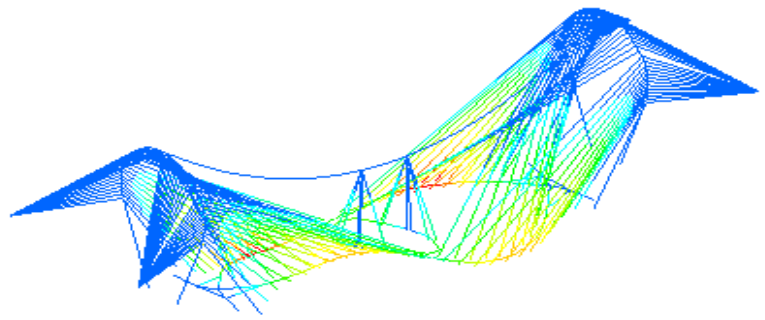

(c) 3 order mode $(0.896 \mathrm{HZ})$

(Antisymmetric side bend)

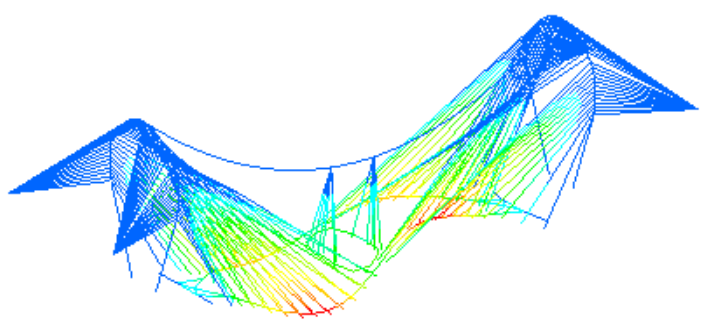

(d) 4 order mode $(0.925 \mathrm{HZ})$

(Antisymmetric side bend)

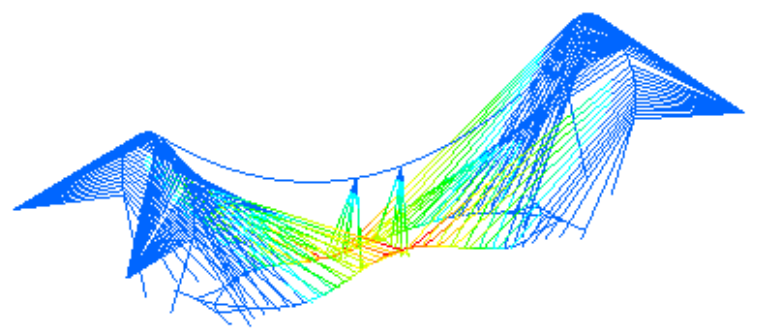

(e) 5 order mode $(1.035 \mathrm{HZ})$

(Positive symmetric vertical bending)

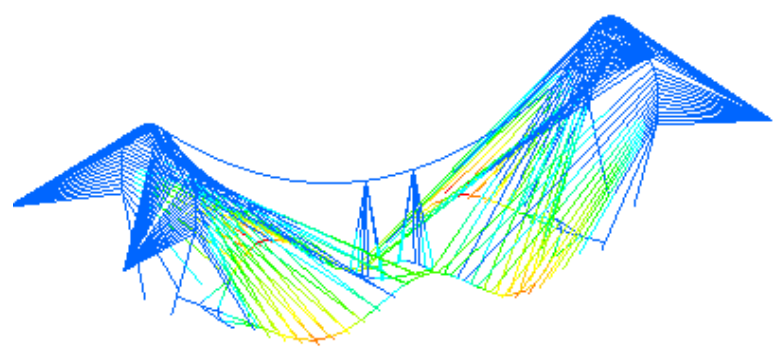

(f) 10 order mode $(1.358 \mathrm{HZ})$

( The deck to reverse)

Figure 10. Typical vibration mode

According to the calculation results in the figure above, the first-order mode is positively symmetrical lateral bending with a high frequency of $0.740 \mathrm{~Hz}$. The second mode is the positive symmetrical vertical bend and the frequency is $0.790 \mathrm{~Hz}$, indicating that the vertical and lateral stiffness of the New Ruck Bridge structure is relatively large. The 10th order mode is torsional, and the positive symmetrical torsional frequency is $1.358 \mathrm{~Hz}$, which indicates that it has good torsional stiffness and strong spatial integrity of the structure.

On the whole, the vibration modes are dense, and there is an obvious pattern grouping phenomenon. The first 10 vibration modes are mainly side bending and vertical bending vibration, and the positive symmetrical torsional 
vibration mode does not appear until the 10th order. The torsional bending frequency ratio of 1.84 is high, indicating that the structure has a good wind-resistant stability.

\section{Conclusion}

In this paper, a Midas finite element model was established against the background of the New Ruck Bridge, a canyon river topography with a span of 400 meters. The static analysis was carried out under vertical load, and the dynamic modal analysis was carried out, and the following conclusions were drawn:

(1) to improve the original firm single curved cablestayed bridge for elliptic ring type double amplitude curve girder, set up the duck eggs arch bridge tower, the four cable plane space network cable arrangement, four cables of cable plane space curved surface has kept a elliptic ring double curved line girders, form the river canyon terrain space plane, four double curved cable-stayed bridge, the curved beam type cable-stayed bridge structure performance is improved and improve the traffic function, improve the landscape effect, construction is convenient, beautiful modelling.

(2) The elliptic circular double-bent main beam, duck egg arch Bridge tower and four-cable surface space cable network of New Ruck Bridge are all curved structure forms, with clever coordination and simple structure. The four-cable surface space cable is novel and unique in modeling, which is an ideal combination of structural science and architecture.

(3) Under the action of vertical constant live load, the maximum vertical displacement occurs in the middle of the span, and the maximum displacement is $0.280 \mathrm{~m}$, which meets the requirements of the specification.

The internal force of single main cable suspension is $80019 \mathrm{kN}$, and the stress is $407 \mathrm{MPa}$, which meets the strength requirements.

The maximum internal force of the stay cable is $18758 \mathrm{kN}$, and the maximum stress of the stay cable is 933.0mpa, which meets the strength requirement.

Under the vertical load, the stress of New Ruck Bridge Bridge structure is symmetrical, without great torsion displacement and stress.

(4) the first ten order modes are mainly composed of lateral and vertical bending vibration, the first order vibration mode of symmetric lateral bending, the fundamental frequency of $0.740 \mathrm{~Hz}$ is higher, shows that the New firm Bridge, the Bridge structure of the vertical and lateral stiffness is bigger, didn't appear until the 10th order is symmetric torsional vibration model, are symmetric torsional frequency of $1.358 \mathrm{~Hz}$ is higher, twisted the frequency ratio of 1.84 is higher, shows that the New firm Bridge, the Bridge structure space integrity is strong, the structure stability of wind resistance is better.

\section{References}

1. H. Bangben, Introduction to the Design of THE American Ruck-A-Chuky Bending bridge [J].Foreign Highways, 1980(01):58 (in Chinese)
2. Takenouchi, Kyo. Aesthetics of cable-stayed bridges with spatial cable form -conoid ruled surface, along a curved $\operatorname{deck}[\mathrm{J}]$. Journal of the International Association for Shell and Spatial Structures, 1997,38,(124),91-98.

3. HUNG, G. M., \& STUCCHI, F. R. Conception of cable-stayed curved deck: the effects of unilateral suspension / Concepção de tabuleiros curvos e estaiados: os efeitos da suspensão unilateral[J]. Revista IBRACON de Estruturas e Materiais, 2018,11(4), 686-695.

4. Galante Bardín, D., \& Astiz Suárez, M. L. A. (n.d.). Design of a curved cable-stayed bridge deck's directives, by the funicular and antifunicular curves of the concentric load introduced by the cables[J]. nformes de La Construccion,

2017, 69(548), 1-14.

5. Raftoyiannis, I. G., \& Michaltsos, G. T. (n.d.). Curved-in-plane cable-stayed bridges: A mathematical model[J]. International Journal of Structural Stability and Dynamics,2012, 12(3).

6. Hoffman, J. J. Analytical and field investigation of horizontally curved girder bridges[D]. Iowa State University,2013.

7. Lin, W., \& Yoda, T. Analysis, design and construction of curved composite girder bridges: State-of-the-art. International Journal of Steel Structures,2010, 10(3), 207.

8. Z. Erhua, S. Deshan, Z. Yongtao.Long-span curve girder cable-stayed bridge $\Pi$ shape analysis method research [J]. World bridge, 2017, (5) : 44-48. (in Chinese) 